\title{
PERBEDAAN PENGARUH BACK STRENGTHENING EXERCISE DAN PILATES EXERCISE TERHADAP AKURASI TENDANGAN PADA PEMAIN SEPAK BOLA
}

\author{
Deasy Virka Sari ${ }^{1}$, I Putu Gede Adiatmika ${ }^{2}$, M. Ali Imron ${ }^{3}$, Ni Wayan Tianing ${ }^{4}$, Anak \\ Agung Sagung Sawitri ${ }^{5}$, S. Indra Lesmana ${ }^{6}$ \\ ${ }^{1}$ Program Studi Magister Fisiologi Keolahragaan Universitas Udayana Denpasar Bali \\ 2,4,5 Fakultas Kedokteran Universitas Udayana Denpasar Bali \\ ${ }^{3}$ Program Studi Fisioterapi Stikes Aisyiyah Yogyakarta \\ ${ }^{6}$ Fakultas Fisioterapi Universitas Esa Unggul Jakarta
}

\begin{abstract}
ABSTRAK
Latar Belakang: Akurasi tendangan merepukan gerakan gerakan bebas terhadap suatu sasaran yang dikendalikan oleh kemampuan seseorang. Akurasi tendangan dipengaruhi oleh otot-otot core, konesentrasi dan keseimbangan dinamis. Sehingga untuk meningkatkan akurasi tendangn pada pemain sepak bola peneliti meemberikan latihan back strengthening exercise dan Pilates exercise. Tujuan: untuk mengetahui perbedaan pengaruh back strengthening exercise dan Pilates exercise terhadap akurasi tendangan pada pemain sepak bola. Metode: Penelitian ini menggunakan quasi experimental dengan rancangan pre-test and post-test group design. Pada penelitian ini terdapat 2 kelompok yang terbagi secara acak diambil dari 22 subyek. Kelompok I dengan back strengthening exercise dan kelompok II pilates exercise. Latihan dilakukan sebanyak 3 kali dalam seminggu selama 6 minggu. Alat untuk mengukur akurasi tendangan dengan plywood target measurement. Hasil: penelitian menunjukan bahwa pemberian intervensi pada Kelompok I dan II dapat meningkatkan akurasi tendangan pemain sepak bola. Kelompok I uji pengaruhya menggunakan paired sample ttest. Dengan rata-rata pre dan post tes didapatkan hasil $(\mathrm{p}=0,004)$ serta uji pada Kelompok II didapatkan pre dan post tes didapatkan hasil $(\mathrm{p}=0,011)$. Hasil uji beda pengaruh terhadap kedua sempel perlakuan mengunakan independent sample t-test setelah perlakuan mendapatkan hasil $(\mathrm{p}=$ 0,100) pada kelompok I dan kelompok II. Simpulan: Tidak ada perbedaan pengaruh antara pemberian back strengthening exercise dan Pilates exercise terhadap akurasi tendangan pada pemain bola.
\end{abstract}

Kata kunci: back strengthening exercise, Pilates exercise, sepak bola 


\title{
THE DIFFERENCE EFFECT OF BACK STRENGTHENING EXERCISE AND PILATES EXERCISE TOWARD KICK ACCURACY IN SOCCER PLAYER
}

\begin{abstract}
Background: Kick accuracy is a person's ability to control free movements against a target. Kick accuracy are influenced by core muscles, concentration and dynamic balance. Back strengthening exercise and Pilates exercise was given by the researcher to improve the accuracy of kicking among soccer players. Purpose: The difference effect of back strengthening exercise and Pilates exercise on kick accuracy among soccer players. Methods: This study was quasiexperimental with a pre-test and post-test group design. There were 22 subjects divided randomly into 2 groups. Group I with back strengthening exercise and group II Pilates exercise. Exercise was given 3 times a week for 5 weeks. Kick accuracy measurement tool used plywood target measurement. Result: research shows that the intervention that was given to groups I and II could improve kick accuracy in soccer players. The effect test are using paired sample t-test in group I with mean pre and post test, obtained $(\mathrm{p}=0.004)$ and in group II obtained $(\mathrm{p}=0.011)$. The different test among two groups are using independent sample t test with post treatment data in each group, obtained $(\mathrm{p}=0.100)$. Conclusion: There is no difference in the effect between giving back strengthening exercise and Pilates exercise to the accuracy of kick on the soccer player.
\end{abstract}

Key words: back strengthening exercise, Pilates exercise, football 


\section{PENDAHULUAN}

Permainan sepak bola membutuhkan kondisi fisik dan taktik untuk mencapai kemenangan, tetapi juga dibutuhkan teknik yang baik dan benar sehingga kemenangan yang diharapkan dalam pertandingan bukan lagi menjadi hal yang mustahil untuk dicapai. Teknik dasar dalam sepak bola salah satu yang paling penting adalah tendangan bola yang tepat dan akurat. Mencapai teknik menendang bola yang benar tentu saja dibutuhkan kajian biomekanik yang jelas dan terukur sehingga pelatih fisik dalam sepak bola bisa memberikan edukasi tentang bagaimana cara menendang yang benar ataupun program latihan apa yang akan diberikan. ${ }^{1}$

Berbagai bentuk latihan untuk menguatkan postural atau core stability adalah dengan memberikan latihan Pilates Exercise, selain itu juga terdapat back strengthening exercise. Core stability exercise sendiri membantu dalam menambah kemampuan pemain untuk mengendalikan atau mengontrol gerakan dan posisi central pada tubuh diantaranya head and neck aligament, aligament of vetebral column thorax and pelvic stability/mobility, and ankle hip strategies. Pilates Exercise adalah bentuk latihan penguatan (strengthening) dan peregangan (stretching) pada bagian pelvis antara core, vertebra dan abdominal dengan tujuan untuk membantu menstabilkan posisi tubuh baik diam ataupun bergerak. ${ }^{2}$

Back strengthening sendiri mengacu pada komponen aktif pada sistem penstabil termasuk otot dalam atau lokal yang memberikan stabilitas segmental (misalnya transversus abdominis, multifidus lumbal) dan atau otot superfisial global (misalnya rektus abdominis, erector spine) yang memungkinkan pergerakan batang/torsi generasi dan juga membantu dalam stabilitas dalam tugas yang lebih menuntut secara fisik., manfaat lain Back strengthening exercise adalah untuk memperbaiki postur keseluruhan dan juga memberikan kemudahan seseorang untuk melakukan gerakan yang biasanya memunculkan rasa sakit, seperti membungkuk, memutar, atau mengangkat.

Back strengthening exercise sendiri jika dilihat dari manfaatnya lebih menekankan kepada stabilitas otot segmental dan otot superfisial global dengan tujuan keseimbangan tubuh akan terjaga kestabilannya pada saat bergerak, dan juga mengkondisikan otot-otot untuk lebih mendukung tulang belakang dalam mengurangi stress, sedangkan Pilates exercise yang lebih menekankan kontrol dan kendali posisi dari gerakan central tubuh dan juga mengurangi resiko cidera tubuh, mengurangi resiko cedera tubuh, meningkatkan performa gerakan, mengkuatkan otot, memperbaiki postur tubuh, keseimbangan tubuh, kesadaran tubuh, mengurangi berat badan. ${ }^{3}$

Tujuan penelitian ini membuktikan perbedaan pengaruh back strengthening exercise dan Pilates exercise terhadap akurasi tendangan pada pemain sepak bola.

\section{METODE PENELITIAN}

\section{A. Rancangan Penelitian}

Penelitihan ini bersifat quasi experimental dengan rancangan pre and post test group design. Back strengthening exercise diberikan kepada kelompok I dan pilates exercise diberikan kepada kelompok II. Semua Kelompok tersebut diberikan perlakuan 3 kali seminggu selama 6 minggu.

\section{B. Tempat dan Waktu Penelitian}

Dilaksanakan penelitian ini bertempat di Lapangan Kota Barat Surakarta pada bulan Januari hingga bulan Februari 2018.

\section{Populasi dan Sampel}

Populasi penelitian adalah semua anak yang menjadi anggota PFA FC yang telah memenuhi syarat kriteria inklusi dan kriteria eksklusi sebagai sampel penelitian. Sampel 
berjumlah 22 orang yang dipilih dengan cara random sampling.

\section{Prosedur Penelitian}

Prosedur pada tahap penelitian meliputi : (a) Survei objek penelitian PFA FC dan lapangan tempat penelitian, (b) membuat surat perijinan kepada ketua pengurus PFA FC untuk meminta kesediaan anak asuhnya dijadikan sampel dalam penelitian yang akan dilakukan, (c) Pengambilan sampel penelitian, kemudian mengambil nilai awal penelitian dengan menggunakan plywood target measurement, (e) memberikan intervensi sesuai dengan pembagian kelompok I dan II, yaitu dengan memberikan back strengthening exercise dan pilates exercise dilaksanakan selama 6 minggu sebanyak 3 kali dalam seminggu, setelah pemberian intervensi kemudian dilakukan pengambilan nilai akhir akurasi tendangan dengan menggunakan instrumen pengukuran yang sama (e) semua data statistik diolah menggunakan komputer dengan program SSPS.

\section{E. Analisis Data}

Sebelum dilakukan uji statistik terlebih dahulu dilakukan uji normalitas dan homogenitas data.

1. Uji normalitas data menggunakan Shapiro Wilk Test didapatkan hasil p > 0,05 maka data berdistribusi normal.

2. Uji homogenitas data menggunakan Levene's test didapatkan nilai signifikan lebih besar dari 0,05 ( $>0,05)$ maka data bersifat homogen.

3. Uji parametrik menggunakan paired sample t-testdan independent sample ttest. Batas kemaknaan yang digunakan adalah $\mathrm{a}=0,05$.

\section{HASIL PENELITIAN}

\section{Deskripsi Karakteristik Subjek Penelitian \\ Deskripsi data merupakan karakteristik} sampel penelitihan dalam bentuk tabel. Berikut ini adalah deskripsi karakteristik sampel yang terdiri dari IMT, tinggi badan, berat badan, usia (Tabel 1).

Tabel 1

Distribusi Data Sampel

\begin{tabular}{|c|c|c|c|c|c|}
\hline \multirow[t]{2}{*}{ Karakteristik } & \multirow[t]{2}{*}{ Kategori } & \multicolumn{2}{|c|}{$\begin{array}{c}\text { Kelompok } \\
\text { I }\end{array}$} & \multicolumn{2}{|c|}{$\begin{array}{c}\text { Kelompok } \\
\text { II }\end{array}$} \\
\hline & & $\mathrm{F}$ & $\%$ & $\mathrm{~F}$ & $\%$ \\
\hline \multirow{2}{*}{ Umur (th) } & 16 & 7 & $63,6 \%$ & 6 & $54,5 \%$ \\
\hline & 17 & 4 & $36,4 \%$ & 5 & $45,5 \%$ \\
\hline \multirow[t]{2}{*}{ TB (cm) } & $160-170$ & 7 & $63,6 \%$ & 7 & $63,6 \%$ \\
\hline & $171-180$ & 4 & $36,4 \%$ & 4 & $36,4 \%$ \\
\hline \multirow[t]{3}{*}{$\overline{\mathrm{BB}}(\mathrm{kg})$} & $50-60$ & 6 & $54,5 \%$ & 6 & $54,5 \%$ \\
\hline & $61-70$ & 4 & $36,4 \%$ & 5 & $45,5 \%$ \\
\hline & $71-80$ & 1 & $9,1 \%$ & - & $0 \%$ \\
\hline \multirow[t]{2}{*}{ IMT $\left(\mathrm{kg} / \mathrm{m}^{2}\right)$} & $15-20$ & 4 & $36,4 \%$ & 5 & $45,5 \%$ \\
\hline & $21-25$ & 7 & $63,6 \%$ & 6 & $54,5 \%$ \\
\hline
\end{tabular}

\section{Uji Normalitas dan Homogenitas}

Tabel 2

Hasil Uji Normalitas dan Homogenitas

\begin{tabular}{cccc}
\multirow{2}{*}{$\begin{array}{c}\text { Kelompok } \\
\text { data }\end{array}$} & \multicolumn{2}{c}{ Uji Normalitas dengan } & Uji \\
\cline { 2 - 3 } & Shapiro WilkTest & Homogenitas \\
& $\begin{array}{c}\text { Kelompok 1 } \\
(p)\end{array}$ & Kelompok 2 & data \\
& $(p)$ & $\begin{array}{c}\text { Levene' test } \\
(p)\end{array}$
\end{tabular}

Skor Akurasi

Tendangan $\quad 0,258 \quad 0,215$

Sebelum

Skor Akurasi

Tendangan $\quad 0,374 \quad 0,200$

Sesudah

Berdasarkan Tabel 2 pada kelompok I dan kelompok II menunjukan hasil uji normalitas sebelum perlakuan dan setelah perlakuan menunjukkan bahwa data berdistribusi normal. Dari uji homogenitas dengan Levene's test pada data sebelum perlakuan kedua kelompok menunjukkan $\mathrm{p}>0,05$ menyatakan bahwa kedua kelompok bersifat homogen.

\section{Uji beda akurasi tendangan sebelum dan sesuadah perlakuan}


Tabel 3

Hasil Uji beda akurasi tendangan sebelum dan sesuadah perlakuan

\begin{tabular}{|c|c|c|c|}
\hline \multirow{2}{*}{ Kelompok } & $\begin{array}{c}\text { Sebelum } \\
\text { Perlakuan } \\
\end{array}$ & $\begin{array}{c}\text { Setelah } \\
\text { Perlakuan }\end{array}$ & \multirow{2}{*}{$\begin{array}{c}\text { Nilai } p \\
\text { (paired } \\
\text { simple } t \text {-tes) }\end{array}$} \\
\hline & Rerata \pm SB & Rerata \pm SB & \\
\hline I & $4,82 \pm 0,701$ & $6,36 \pm 0,674$ & 0,004 \\
\hline II & $5,09 \pm 0,751$ & $6,36 \pm 0,505$ & 0,011 \\
\hline $\begin{array}{c}\text { Nilai } p \\
\text { (independent } \\
\text { sample t-tes ) }\end{array}$ & 0.389 & 0,100 & \\
\hline
\end{tabular}

Berdasarkan Tabel 3 menunjukan hasil pengolahan data uji pengaruh menggunakan uji paired sample t-test pemberian back strengthening exercise terhadap akurasi tendangan yang menunjukkan bahwa ada pengaruh pemberian back strengthening exercise terhadap nilai akurasi tendangan sebelum dan sesudah pada pemain sepakbola. Pada hasil pengolahan data uji pengaruh menggunakan uji paired sample t-test pemberian pilates exercise terhadap akurasi tendangan mendapatkan hasil nilai signifikansi adalah $\mathrm{p}=0,011 \quad(\mathrm{p}<0,05)$ yang berarti bahwa ada pengaruh pemberian Pilates exercise terhadap akurasi tendangan sebelum dan sesudah pada pemain sepakbola.

Dari nilai akurasi tendangan sebelum perlakuan menggunakan Independent sampel $t$ test pada Kelompok I dan Kelompok II diperoleh nilai $p=0,389(p>0,05)$ yang berarti bahwa tidak ada perbedaan makna, sedangkan untuk nilai akurasi tendangan pada kedua kelompok didapatkan nilai $\mathrm{p}=0,100(\mathrm{p}>0,05)$ yang menunjukkan bahwa tidak ada perbedaan makna.

\section{PEMBAHASAN}

1. Back strengthening exercise dapat meningkatkan akurasi tendangan pada pemain sepak bola.
Hasil analisis data hipotesis persentase nilai kemampuan akurasi tendangan dengan pemberian back strengthening exercise antara tes awal dengan tes akhir diperoleh nilai $\mathrm{p}=0,004 \quad(\mathrm{p}<0,05) \quad$ dengan menggunakan paired sample t-test artinya ada peningkatan kemampuan akurasi tendangan pada pemain sepak bola.

Back strengthening exercise dalam mekanismenya yang menguatkan otot-otot core akan memberikan efek ke dalam tubuh pemain sepak bola yang dalam aktivitas fisiknya lebih dominan digunakan untuk bergerak baik berpindah tempat ataupun melakukan teknik gerakan sepak bola, baik menendang bola, menyundul bola ataupun menerima bola, kekuatan otot-otot core yang bagus pada pemain sepak bola yang dihasilkan dari pemberian back strengthening exercise akan memberikan postural support yang bagus dalam kegiatankegiatan tersebut. Kebutuhan gerak yang dinamis pada pemain sepak bola tentu saja dibutuhkan kontrol posisi dan gerak dari trunk sampai pelvic, dan back strengthening dalam gerakan-gerakan yang dilakukan memberikan kekuatan untuk menstabilkan kebutuhan gerakan tersebut terlebih lagi dalam gerakan dinamik yang dilakukan oleh pemain sepak bola. ${ }^{4}$

\section{Pilates exercise dapat meningkatkan kemampuan akurasi tendangan pada pemain sepak bola}

Hasil penelitian dari data persentase nilai akurasi tendangan pada Pilates exercise selama 6 minggu didapatkan rerata hasil sebelum perlakuan sebesar 5,09 $\pm 0,751$ dan setelah perlakuan sebesar $6,36 \pm 0,505$ artinya ada perbedaan rerata nilai kemampuan akurasi tendangan sebelum dan setelah perlakuan. Hasil analisis data hipotesis nilai kemampuan akurasi tendangan dengan intervensi Pilates exercise antara tes awal dengan tes akhir diperoleh nilai $\mathrm{p}=0,011 \quad(\mathrm{p}<0,05) \quad$ dengan menggunakan paired sample t-test dapat 
disimpulkan bahwa Pilates exercise dapat meningkatkan akurasi tendangan pada pemain sepak bola.

Pilates exercise memberikan pengajaran bagaimana melatih pikiran dan membangun simetri dan koordinasi dalam tubuh, selain itu mendidik kesadaran tubuh saat bergerak, sehingga tubuh akan akan lebih terkontrol dalam setiap geraknya. Selain itu menurut Galiano yang terpenting dari Pilates exercise adalah bahwa dalam latihan tersebut sangat bermanfaat terhadap peningkatan kekuatan pada punggung belakang, keseimbangan serta fleksibilitas pada saat tubuh dalam kondisi diam ataupun bergerak. ${ }^{5}$

Pengaruh Pilates exercise sendiri terhadap akurasi tendangan juga berhubungan dengan core stability, keseimbangan core, centering of body baik secara fleksibilitas dan kekuatan yang seimbang yang dihasilkan dari latihan ini tentu saja akan menciptakan kestabilan postural pemain sepak bola. Pada saat melakukan tendangan rata-rata lingkup geral pelvic dari posisi retraksi ke protraksi pada saat kaki bersentuhan dengan bola pada saat menendang tercatat sekitar $30^{\circ}$ dan $36^{\circ}$. Meningkatnya kestabilan lumbopelvic dengan otot-otot corenya yang dihasilkan dari pilates exerice maka diharapkan akan membantu mengontrol gerakan lumbo pelvic agar tetap dalam lingkup sudut sekitar $30^{\circ}$ dan $36^{\circ} .6$

\section{Back strengthening exercise dan Pilates exercise tidak memiliki perbedaan pengaruh terhadap peningkatan akurasi tendangan pada pemain sepak bola}

Uji beda pengaruh pemberian back strengthening exercise dan Pilates exercise tidak mendapatkan perbedaan pengaruh, hal ini dilihat dari uji beda pengaruh Independent Sampel t test yang mendapatkan nilai signifikansi $\mathrm{p}=0,389(\mathrm{p}>0,05)$ pada nilai sebelum perlakuan, dan nilai $\mathrm{p}=0,100$ ( $p>0,05)$ pada nilai sesudah perlakuan. Back strengthening exercise dan Pilates exercise walaupun sama-sama berpengaruh tetapi tidak memiliki perbedaan yang membuat kedua perlakuan tersebut dapat dikatakan signifikan, meski dalam nilai rata-rata memiliki perbedaan. Kedua bentuk latihan ini berfokus kepada peningkatan kemampuan core stability, back strengthening exercise dan Pilates exercise ternyata tidak memberikan hasil yang signifikan dalam perbedaan terhadap akurasi tendangan. ${ }^{7}$

Kerja core stability menghasilkan suatu pola adanya stabilitas proksimal yang digunakan untuk mobilitas pada distal. Pola proksimal ke distal yaitu gerakan berkesinambungan yang menjaga sendi pada distal yang digunakan untuk mobilisasi saat bergerak. ${ }^{8}$

Latihan core stability akan memberikan beberapa keuntungan pada atlet olahraga, diantaranya adalah meningkatkan efesiensi gerak, meningkatkan kontrol tubuh dan keseimbangan, meningkatkan kekuatan otototot core dan otot-otot anggota gerak seperti bahu, lengan dan tungkai. Dismaping itu bahwa core stability juga dapat menurunkan resiko cedera (kerja otot-otot core seperti peredam kejut saat gerak lompat,berbalik, dan sebagainya). ${ }^{9}$

\section{SIMPULAN}

Dari penelitian ini dapat disimpulkan sebagai berikut :

1. Latihan Back Strengthening Exercise dapat meningkatkan akurasi tendangan pada pemain sepak bola.

2. latihan Pilates exercise dapat meningkatkan akurasi tendangan pada pemain sepak bola.

3. Tidak ada perbedaan pengaruh Back Strengthening Exercise dan Pilates exercise terhadap akurasi tendangan pada pemain sepak bola. 


\section{DAFTAR PUSTAKA}

1. Herwin. 2004. Keterampilan Sepakbola Dasar. Diktat Pembelajaran. FIK UNY.

2. Bryden, Lincoln. 2009. Stability Ball Exercises. Lincoln Bryden, Stability Ball Ecourse, March 2009. Diaskes pada tanggal 24 Oktober 2017 dari: www.fitnesstrainingforlife.com.

3. Fredericson, Michael. Venu Akuthota,Andrea Ferreiro, Tamara Moore. 2008. Core Stability Exercise Principles. Curr.Sports Med.Rep., Vol. 7, No. 1, pp. 39Y44, 2008.

4. Rini, Galuh LC. 2016. Pengaruh Pemberian Core Stability Exercise Untuk Peningkatan Keseimbangan Dinamik Pada Pemain Sepak Bola Putra Maospati Di Kabupaten Magetan. Universitas Muhammadiyah Surakarta.

5. Galliano, Siri Dharma. 2012. The Benefit of Pilates. Pilates Method Alliance.

6. Kloubec, J.A. 2010. Pilates for Improvment of Muscle Endurance. Flexibility, Balance and Posturale. J Strenght Cod Res. 661-667.

7. Rubenstein, Irv. 2005. Editors. Exercise Ideas For Core Strengthining. Wasington: fisual healte information.

8. Shah, Salvi. 2013. Pilates Exercise. International Journal of Physiotherapy and Research, Int J Physiother Res 2013, Vol1(4):196-203. ISSN 2321-1822.

9. Okada, Tomoko. Tincher, Jeffery, Huxel, Kellie. Nesser, Thomas. 2008. The Relationship Between Core Stability and Performance In Division I Football Players. 22(6)/1750-1754. Journal of Strength and Conditioning Research. 